\title{
PENGARUH KOMPENSASI TERHADAP DISIPLIN KARYAWAN DI PT.PUTERA PAPAN HUTAMA
}

\author{
${ }^{1}$ Indra Sasangka, ${ }^{2}$ Asep Suwarna, ${ }^{3}$ Rana Juliansyah \\ 1, 2, ${ }^{3}$ Sekolah Tinggi Ilmu Ekonomi Muhammadiyah Bandung \\ ${ }^{1}$ Email: indrasasangka74@gmail.com
}

\begin{abstract}
Abstrak
Pelaksanaan kegiatan atau aktifitas dalam suatu organisasi pada dasarnya ditujukan untuk mencapai sasaran atau tujuan yang telah ditetapkan sebelumnya kinerja karyawan adalah hasil kerja karyawan dalam menjalankan tugas sesuai dengan tanggung jawab yang dibebankan semua karyawan. Kompensasi mencerminkan status, pengakuan dan tingkat pemenuhan kebutuhan yang dinikmati oleh karyawan dan keluarga sehinggga dapat mempengaruhi kepuasan kerja karyawan. Kompensasi diyakini akan mempengaruhi disiplin dan kinerja karyawan PT. Putera Papan Hutama.

Metode penelitian yang digunakan adalah metode deskriptif verivikatif dengan pendekatan studi kasus, dengan tekhnik pengumpulan data menggunakan daftar pertanyaan yang disusun berdasarkan lima skala pilihan terhadap 37 karyawan PT. Putera Papan Hutama sebagai responden. Tekhnik pengolahan data yang digunakan adalah menggunakan analisis koefisien korelasi, regresi linier sederhana dan kooefisien determinan.

Dengan menggunakan program software SPSS ditemukan hasil pegaruh kompensasi terhadap disiplin karyawan PT. Putera Papan Hutama sebesar 65,4 \% dan 34,6 \% dipengaruhi variable lain yang tidak diteliti.

Kata kunci : Kompensasi, Disiplin
\end{abstract}

\begin{abstract}
Implementation of the activity or activities in an organization is busy cally intended to achieve the goals or objectives that have been shet he previously. Employee performance is the work of employees in performing their duties in accordance with the responsibilities assigned to all employees. Compentation is believed to affect the performace of the employess discipline and PT Putera Papan Hutama.

The method used is descriptive method verivikatif case study approach, using data collected with a list of question prepared by the scale option five to 37 employees PT Putera Papan Hutama as the respondent. Data processing technique used is to use the correlation coefificient analisis, Sample linear regression coefficients and determinants.

By using the SPSS software program to find The effect compentation amounting the value of employees disciplined PT Putera Papan Hutama by $65,4 \%$ and 34,6 \% is influenced by other variables that are not in meticulous.

Key word : Compentation, Disciplined

\section{PENDAHULUAN}

Perusahaan atau organisasi tertetu

dalam memberikan kompensasi hendaklah

secara objektif dan relevan dengan

berpedoman terhadap undang-undang ketenaga kerjaan tahun 2003 pasal 89 ayat 1 poin b, Upah minimum berdasarkan pada sektor wilayah provinsi atau kabupaten/kota.
\end{abstract}


Dan pasal 90 ayat 1, Pengusaha dilarang membayar upah lebih rendah dari upah minimum sebagai mana dimaksud dalam pasal 89, SK Gubernur Jawa barat no.561/1746Bangsos/2014, pada poin 14SK Gubernur Jawa barat no.561/1581-Bangsos/2015 Upah minimum kabupaten/ kota di jawa barat.

Kompensasi merupakan faktor utama untuk memenuhi berbagai kebutuhan tenaga kerja dalam mencukupi kehidupan keluarganya, pembayaran kompensasi hendaknya selalu tepat waktu, dengan mempertimbangkan kebutuhan yang tidak dapat ditunda seperti makan dan kesehatan, maka suatu kewajiban bagi perusaahan dalam memberikan kompensasi yang layak terhadap karyawannya.

PT. Putera Papan Hutama selaku developer property dengan jumlah karyawan sebanyak 37 orang berada diwilayah kota bandung yang mengedepankan kualitas dengan tujuan utamanya yaitu mengejar kepuasan konsumen dalam penjualan rumah, sudah pasti mengharapkan tingkat disiplin karyawan yang tinggi. Namun mayoritas karyawannya hanya mendapat kompensasi berupa gaji, uang makan ditambah dengan kepesertaan BPJS serta tunjangan hari raya saja tanpa ada upah lainnya, disamping itu pretasi juga tidak dijadikan nilai tambah dalam pemberian kompensasi.
Tingkat penggajian karyawan sesuai

dengan pendidikan dan jabatan pada tiaptiap bagian

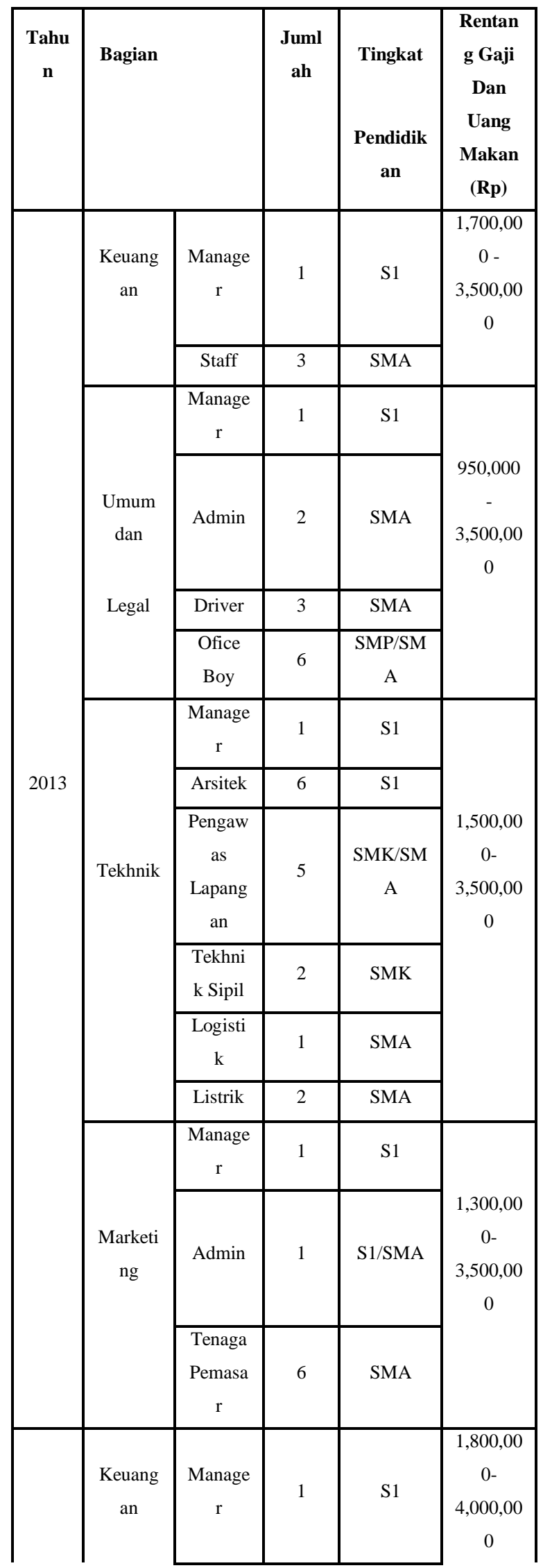




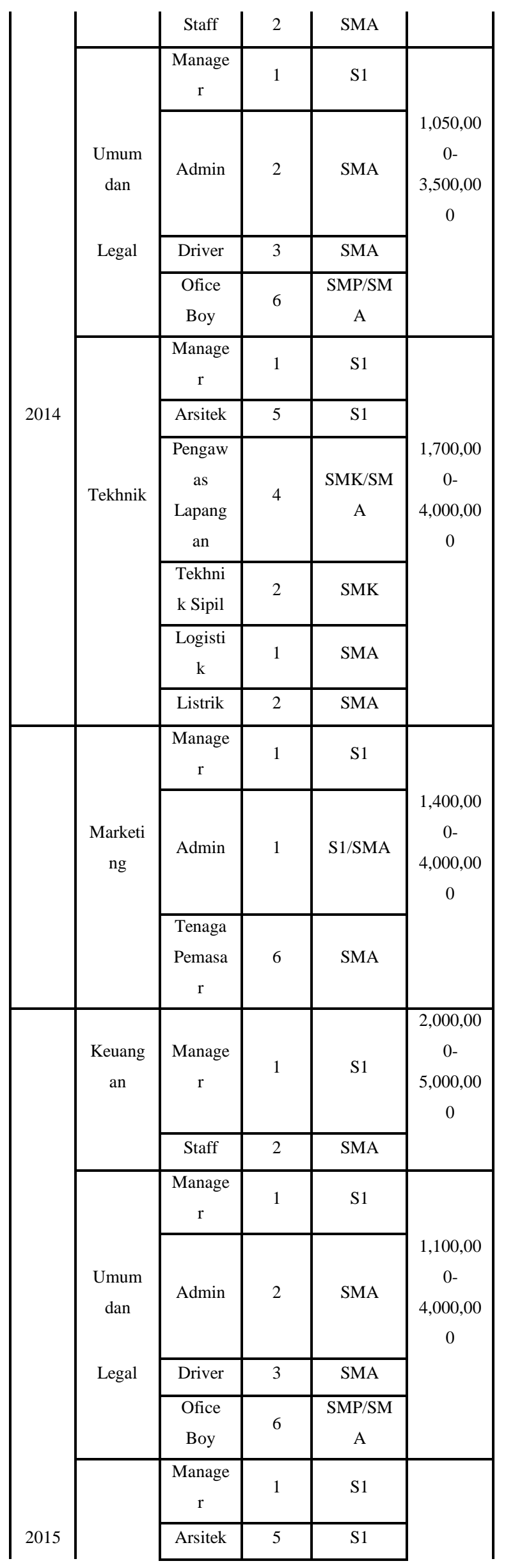

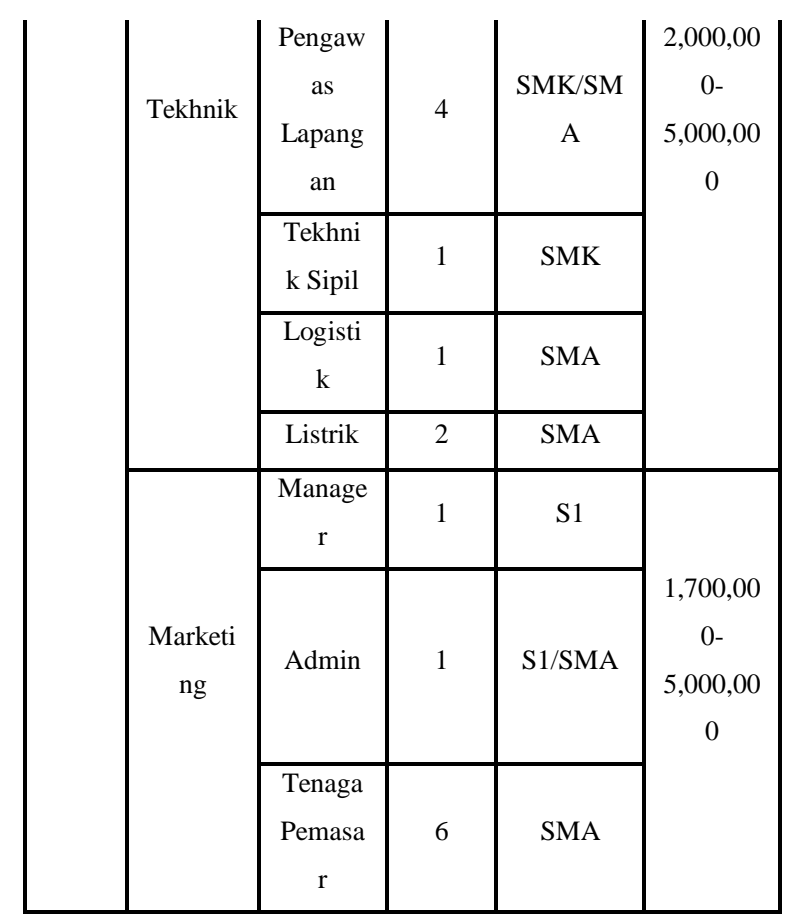

Sumber PT.PPH 2015

Kompensasi menurut Hasibuan (2013:118) Kompensasi adalah semua pendapatan yang berbentuk uang, barang langsung atau tidak lansung yang diterima karyawan sebagai imbalan atau jasa yang diberikan kepada perusahaan.

\section{Tingkat kehadiran dan Turn over}

\section{karyawan 2013-2015}

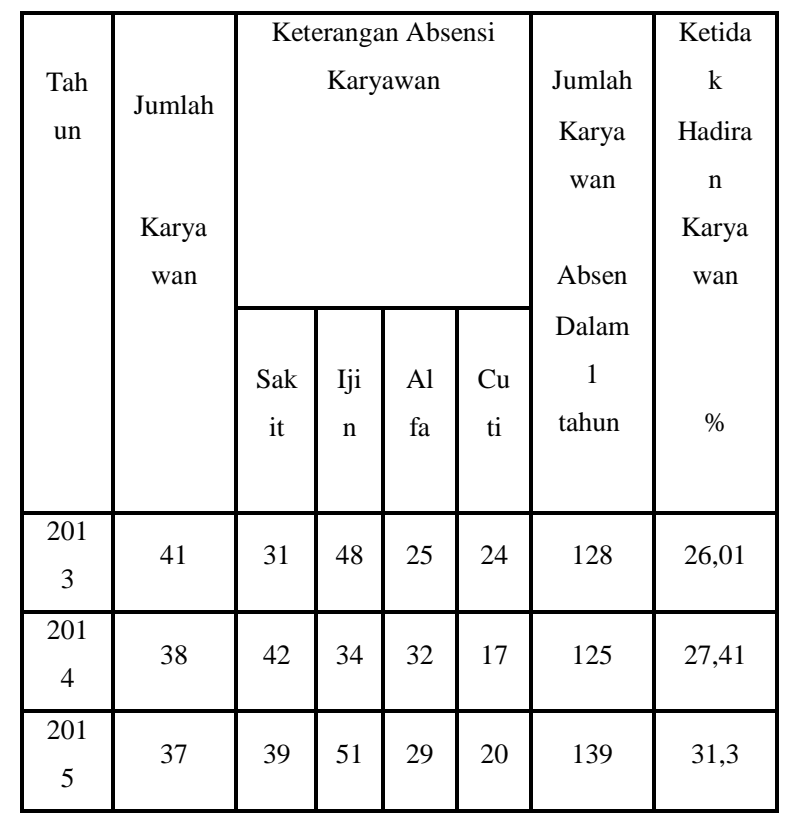


Mulyadi $(2015 ; 67)$ menyatakan :

"Disiplin adalah merupakan sikap hormat yang tertanam pada diri karyawan, terhadap peraturan perusahaan".

Pengertian Kompensasi menurut William B.Werther dan Keitth Davis yang dikutif oleh Hasibuan (2013:119):

"Kompensasi adalah apa yang seorang pekerja terima sebagai balasan dari pekerjaan yang diberikannya. Baik upah perjam atau gaji periodic di desain dan dikelola oleh bagian personalia"

Diperjelas Pengertian kompensasi menurut Hasibuan (2013:118)

Kompensasi adalah semua pendapatan yang berbentuk uang, barang langsung atau tidak lansung yang diterima karyawan sebagai imbalan atau jasa yang diberikan kepada perusahaan.

Kompensasi yang diberikan perusahaan pada karyawan bisa digolongkan menjadi beberapa jenis. Mulyadi $(2015 ; 12)$ mengemukakan, kompensasi dikategorikan menjadi 2 jenis, antara lain :

1. Kompensasi Langsung

Kompensasi langsung adalah kompensasi yang langsung bisa diterima seorang karyawan seperti : gaji, bonus, THR

\section{Kompensasi Tidak Langsung}

Kompensasi tidak langsung adalah kompensasi yang tidak langsung bisa berupa penghargaan atau berupa pekerjaan dan lingkungan pekerjaan dan bisa berupa berbagai fasilitas dan tunjangan lainnya.

Menurut Hasibuan (2012:118) yaitu:
1. Kompensasi langsung (direct compensation) atau berupa gaji,upah dan upah insentif

2. Kompensasi tidak langsung (indirect compensation) atau employee welfare atau kesejahteraan karyawan.

Dari pengertian di atas dapat disimpulkan bahwa kompensasi merupakan balas jasa yang diterima oleh seorang, karena telah memberikan atau menyumbankan tenaga, pikiran ide-ide terhadap suatau perusahaan.

Pemberian kompensasi atau balas jasa merupakan salah satu kebijakan pimpinan perusahaan dalam upaya memenuhi kebutuhan hidup para karyawan guna meningkatkan semanagat kerja karyawan dalam melaksanakan pekerjaannya. Dengan kebijakan kompensasi yang baik diharapkan para karyawan memiliki kinerja yang tinggi dalam bekerja sehingga akan diperoleh output yang lebih besar.

Mulyadi $(2015 ; 67)$ menyatakan :

"Disiplin adalah merupakan sikap hormat yang tertanam pada diri karyawan, terhadap peraturan perusahaan".

Faktor yang mempengaruhi dispilin menurut Mulyadi (2015:54)

1. Pengaruh pemerintah

2. pengaruh keteladanan pimpinan dalam perusahaan

3. Adanya aturan atau tolak ukur yang pasti dijadikan pegangan

4. Faktor ketegasan pimpinan dalam mengambil keputusan 
5. Faktor adanya pengawasan dari pimpinan

6. Faktor perhatian kepada karyawan

7. Faktor yang mendukung tegaknya disiplin

Menurut Mulyadi (2015:81) :

"Manusia atau karyawan dan seorang individu mempunyai kebutuhan berupa materiil dan non materiil, kebutuhan hidup ini dapat memotivasi seorang pekerja.

Tujuan kompensasi menurut Hasibuan $(2012: 121)$

Ikatan kerja sama, kepuasan kerja, pengandaan efektif, motivasi stabilitas karyawan, disiplin, serta pengaruh serikat buruh dan pemerintah.

Dale Yoder ( Hasibuan 2012:118 ) Mengemukakan "the payment mae to remember of work teams for their participation". Artinya balas jasa membuat anggota tim dapat bekerja sama dan berprestasi.

Menurut Anwar Prabu (2011 : 83 ) Berdasarkan pendapat (kadang-kadang disebut kompensasi) melibatkan pertimbangan atau Andrew itu dapat dikemukakan bahwa proses administrasi upah atau gaji keseimbangan perhitungan. Kompensasi merupakan sesuatu yang dipertimbangakan sebagai suatu yang sebanding. Dalam kepegawaian, hadiah, yang bersipat uang merupakan kompensasi yang diberikan kepada pegawai sebagai penghargaan dari pelayanan mereka. Bentuk - bentuk pemberian upah, bentuk upah, dan gaji digunakan untuk mengatur pemberian keuangan antara majikan dan pegawainya.
Hipotesis pada penelitian ini adalah terdapat pengaruh signifikan antara kompensasi terhadap disiplin karyawan di PT. Putera Papan Hutama.

\section{METODE}

Jenis data yang digunakan dalam penelitian ini adalah:

1. Data primer.

Data primer yaitu data yang dikumpulkan langsung dari responden. Sumber data primer diperoleh dari hasil kuesioner yang diisi oleh seluruh karyawan pada perusahaan itu.

2. Data sekunder.

Data yang diperoleh dari sumber sumber yang sudah dipublikasikan. populasi yang diambil penulis dalam penelitian ini adalah keseluruhan karyawan PT Putera Papan Hutama sebanyak 37 orang. (Keuangan, Umum dan Legal, Tekhnik dan Marketing).

\section{Metode Analisis Data}

Uji Validasi Alat Ukur

Sugiyono (20015:177), Menyatakan bahwa instrument yang valid berarti instrumen tersebut dapat digunakan untuk mengukur apa yang seharusnya di ukur dan bisa ditampilkan. Validity is the extent to wicwh an instrument measures what is supposed to measure and ferforms as it is designed to perform ( http://www.slideshare . net./argellee/theresearch-instruments). Meteran yang valid 
dapat digunakan untuk mengukur panjang dengan tepat/ valid.

Menurut Sugiyono nilai korelasi ( $\mathrm{r}$ ) produk momen dihitung dengan rumus sebagai berikut :

$\frac{r_{x y}=n \sum X Y-\sum X \sum Y}{\sqrt{\left\{n \sum X^{2-}\left(\sum X\right)^{2}\left(n \sum y Y^{2}-\left(\sum Y\right)^{2}\right\}\right.}}$

\section{Keterangan :}

$\mathrm{r}=$ koefisien korelasi item yang dicari

$\mathrm{x}=$ Skor item yang diperoleh subjek dalam setiap item

$\mathrm{Y}=$ Skor total yang diperoleh subjek seluruh item

$\mathrm{n}=$ Jumlah subjek

Sugiyono (2015:184) menyatakan bahwa ketentuan validitas instrument shahih apabila nilai korelasi ( $r$ ) hitung lebih besar dari $r$ kritis yaitu 0,3 .

Selain itu Sugiyono menambahkan bahwa bila korelasi tiap factor positif dan besarnya 0,3 keatas maka faktor tersebut merupakan construct yang kuat.

\section{Uji Reliabilitas Alat Ukur}

Selain memiliki tingkat validitas, alat ukur juga harus memiliki karakteristik reliabilitas. Sugiyono menyatakan bahwa reliabilitas berarti instrument tersebut bila digunakan beberapa kali untuk mengukur objek yang sama akan menghasilkan data sama.Uji Reliabilitas dilakukan dengan mengunakan metode alpha Cronbach's yang diukur berdasarkan skala Alpha Cronbach's 0 sampai 1.

Sugiyono menyatakan bahwa jika skala dikelompokan ke dalam 5 kelas dengan range yang sama maka ukuran kemantapan alpha dapat di interpretasikan sebagai berikut

Nilai alfa cronbach

\begin{tabular}{|l|l|}
\hline $\begin{array}{l}\text { Nilai Alpha Cronbach's 0,0 } \\
\text { s.d. 0,02 }\end{array}$ & Berarti kurang Reliabel \\
\hline Nilai Alpha Cronbach's 0,21 & Berarti Agak Reliabel \\
s.d 0,40 & \\
\hline Nilai Alpha Cronbach's 0,41 & Berarti Cukup Reliabel \\
\hline $\begin{array}{l}\text { Nilai Alpha Cronbach's 0,61 } \\
\text { s.d 0,80 }\end{array}$ & Berarti Reliabel \\
\hline $\begin{array}{l}\text { Nilai Alpha Cronbach's 0,81 } \\
\text { s.d 1,00 }\end{array}$ & Berarti Sangat Reliabel \\
\hline
\end{tabular}

\section{Uji statistic}

\section{Analisis Regresi}

Persamaan regresi yang digunakan adalah persamaan regresi linear sederhana karena hanya meneliti dua variable saja yaitu kompensasi sebagai variable independent $(\mathrm{X})$ dan disiplin karyawan sebagai variable dependent (Y), maka bentuk persamaannya menurut Sugiyono (2004) adalah sebagai berikut:

$$
Y=a+B x
$$

\section{Keterangan:}

$\mathrm{X}=$ subyek dalam variable independent yang mempunyai nilai tertentu.

$\mathrm{Y}=$ subyek dalam variable dependen yang diprediksi

$\mathrm{a}=$ harga $\mathrm{Y}$ jika $\mathrm{X}$ sama dengan nol (harga konstan)

$\mathrm{b}=$ koefisien regresi, yang menunjukkan angka peningkatan $(\mathrm{b}+)$ atau penurunan (b-) variable dependen yang didasarkan pada variable independen. 
Nilai a dan b pada persamaan linier dapat dihitung dengan rumus:

$$
\begin{aligned}
\mathrm{a}= & \frac{\left(\sum \mathrm{Y}\left(\sum \mathrm{X}^{2}\right)\right)-\left(\sum \mathrm{X}\left(\sum \mathrm{XY}\right)\right)}{\mathrm{N} \sum \mathrm{X}^{2}-\left(\sum \mathrm{X}\right)^{2}} \\
\mathrm{~b}= & \frac{\mathrm{n} \sum \mathrm{XY}-\sum \mathrm{X} \sum \mathrm{Y}}{\mathrm{n} \sum \mathrm{X}^{2}-\left(\sum \mathrm{X}\right)^{2}}
\end{aligned}
$$

\section{Koefisien Determinasi}

Koefisien determinasi dimaksudkan untuk menghitung besarnya pengaruh variable (X) yaitu kompensasi terhadap variable (Y) yaitu Disiplin karyawan. Nilai koefisien determinasi dihitung dengan rumus:

$$
\mathrm{Kd}=\mathrm{r}_{\mathrm{s}}^{2} \times 100 \%
$$

\section{Dimana:}

$\mathrm{Kd}=$ koefisien determinasi

$\mathrm{r}_{\mathrm{s}}=$ nilai koefisien korelasi

\section{Pengujian Hipotesis}

Untuk menguji hipotesis yang telah diajukan yaitu pengaruh kompensasi terhadap disiplin karyawan digunakan pengujian hipotesis asosiatif dengan rumus dan hipotesis nol adalah:

Ho $: p=0$, tidak terdapat pengaruh kompensasi terhadap disiplin karyawan di PT Putera Papan Hutama.

Ha :p \# 0, terdapat pengaruh antara kompensasi terhadap disiplin karyawan di PT Putera Papan Hutama.

Ujithitung:

Menurut Sugiyono (2006) untuk hasil hitung dapat disimpulkan jika:

$t_{\text {hitung }} \geq t_{\text {tabel, }}$ maka Ho ditolak, Ha diterima $t_{\text {hitung }} \leq t_{\text {tabel, }}$ maka Ho diterima, Ha ditolak $\mathrm{t}_{\text {hitung }}=\underline{\mathrm{r}(\mathrm{n}-2)}$

$$
\sqrt{ } 1-r^{2}
$$

Keterangan :

$\mathrm{r}=$ nilai korelasi

$\mathrm{n}=$ jumlah sampel

Dengan derajat kebebasan df $=\mathrm{n}-2$ dan taraf nyata digunakan dengan tingkat signifikasi 0,05 dan uji hipotesis satu sisi (one tail test ) sebelah kanan dapat diketahui ho ditolak

\section{HASIL DAN PEMBAHASAN}

\section{Uji Validitas}

Uji validitas digunakan untuk mengukur derajat ketepatan dalam setiap item pertanyaan suatu kuesioner, pertanyaanpertanyaan dalam kuesioner dapat dikatakan valid apabila pertanyaan tersebut mampu mengungkapkan sesuatu yang akan diukur oleh kuesioner tersebut dan apabila nilai korelasi hitung (r hitung) lebih besar daripada nilai korelasinya ( $r$ tabel). Nilai $r$ hitung adalah nilai-nilai yang berada dalam kolom "Correlations" pada lembar output spss. Apabila nilai kolom total correlations $>\mathrm{r}$ tabel, maka item pertanyaan tersebut dapat dikatakan valid.

Setelah dilakukan pengolahan data, diperoleh hasil seperti dibawah ini,

Hasil Uji Validitas Butir Instrumen

Kompensasi

\begin{tabular}{|c|c|r|c|}
\hline Variabel & $\begin{array}{c}\text { Butir } \\
\text { Soal }\end{array}$ & $\begin{array}{r}\text { Corrected } \\
\text { Item-Total } \\
\text { Correlation }\end{array}$ & Keterangan \\
\hline $\begin{array}{c}\text { Kompensasi } \\
(\mathrm{X})\end{array}$ & $\mathrm{X} 1$ & 0,668 & Valid \\
\cline { 2 - 4 } & $\mathrm{X} 2$ & 0,548 & Valid \\
\hline
\end{tabular}




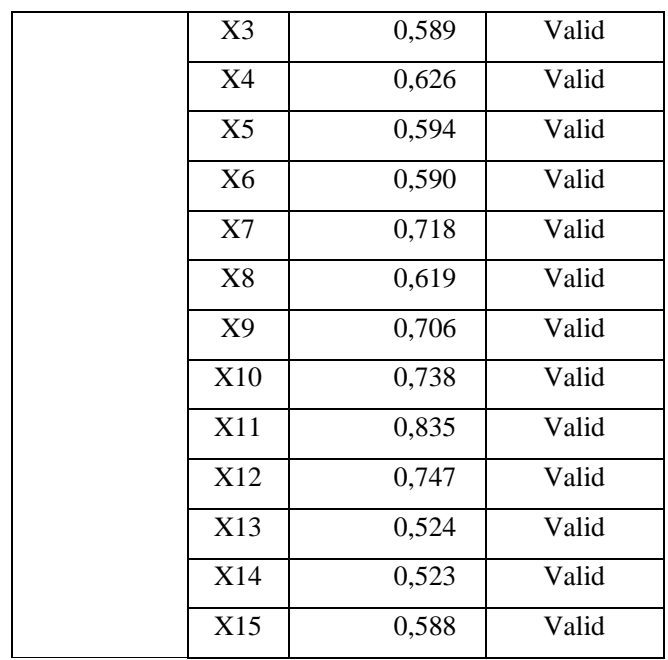

Sumber hasil olah data spss versi 20

Uji Validitas Butir Instrumen Disiplin karyawan

\begin{tabular}{|c|c|c|c|}
\hline Variabel & $\begin{array}{l}\text { Butir } \\
\text { Soal }\end{array}$ & $\begin{array}{c}\text { Corrected } \\
\text { Item-Total } \\
\text { Correlation }\end{array}$ & Keterangan \\
\hline \multirow{15}{*}{$\begin{array}{l}\text { Disiplin } \\
\text { Karyawan } \\
\text { (Y) }\end{array}$} & Y1 & 0,708 & Valid \\
\hline & Y2 & 0,591 & Valid \\
\hline & Y3 & 0,699 & Valid \\
\hline & Y4 & 0,671 & Valid \\
\hline & Y5 & 0,541 & Valid \\
\hline & Y6 & 0,599 & Valid \\
\hline & Y7 & 0,589 & Valid \\
\hline & Y8 & 0,540 & Valid \\
\hline & Y9 & 0,589 & Valid \\
\hline & Y10 & 0,523 & Valid \\
\hline & Y11 & 0,691 & Valid \\
\hline & Y12 & 0,735 & Valid \\
\hline & Y13 & 0,714 & Valid \\
\hline & Y14 & 0,548 & Valid \\
\hline & Y15 & 0,569 & Valid \\
\hline
\end{tabular}

Sumber hasil olah data spss versi 20

Berdasarkan hasil uji validitas butir instrument Kompensasi dan hasil uji validitas butir instrument Disiplin Karyawan di atas menunjukan bahwa setiap pernyataan memiliki indeks validitas nilai $r$ hitung $>$ nilai korelasi (r tabel) 0,300, sehingga dapat disimpulkan bahwa setiap pernyataan yang digunakan untuk mengukur variabel Kompensasi dan variabel Disiplin Karyawan dapat menghasilkan data yang akurat sesuai dengan tujuan penelitian.

\section{Uji Reliabilitas}

Uji reliabilitas adalah indeks yang menunjukan sejauh mana alat pengukur dapat diadakan. Uji reliabilitas digunakan untuk mengukur ketetapan atau kejituan suatu instrumen. Kuesioner dapat dikatakan realibel jika nilai $\mathrm{r}$ alpha positif dan $\mathrm{r}$ alpha $>0,6$, artinya butir pertanyaan atau variabel tersebut adalah dapat dipercaya (realibel). Hasil uji reliabilitas dapat dilihat pada tabel

Hasil Uji Reliabilitas

\begin{tabular}{|c|c|c|}
\hline Variabel & $\begin{array}{c}\text { Cronbach } \\
\text { 's Alpha }\end{array}$ & Keterangan \\
\hline Kompensasi & $0,923$. & Reliabel \\
\hline $\begin{array}{c}\text { Disiplin } \\
\text { Karyawan }\end{array}$ & $0,916$. & Reliabel \\
\hline
\end{tabular}

Sumber hasil olah data spss versi 20, 2016

Dari hasil data uji reliabilitas dari variabel diatas menunjukan bahwa keseluruhan item pertayaan telah memenuhi persyaratan reliabel yaitu nilai Cronbach's Alpa yang dihasilkan >0.60. Hal ini menunjukan bahwa semua pernyataan dan pertanyaan memperoleh data yang konsisten sehingga penyataan ini dapat diajukan kembali dan memperoleh jaawaban yang relatif sama.

\section{Analisis Regresi Linier Sederhana}


Regresi linear adalah metode statistika yang digunakan untuk membentuk hubungan antara variabel terikat dengan variabel independen. Apabila banyaknya variabel bebas hanya satu, maka dapat menggunakan regresi linear sederhana. Bentuk umum regresi linear sederhana adalah sebagai berikut:

$$
\mathbf{Y}=\mathbf{a}+\mathbf{b X}
$$

Dimana : $\mathrm{Y}=$ Variabel dependent ( Disiplin Karyawan )

$$
\begin{aligned}
& \mathrm{a}=\text { Nilai konstanta } \\
& \mathrm{b}=\text { Koefisien regresi } \\
& \mathrm{X}=\text { Variabel independent }
\end{aligned}
$$

(Kompensasi)

Berdasarkan analisis data yang menggunakan perhitungan regresi sederhana dengan program IBM Stastitical for Product and Service Solution (SPSS) versi 20, maka

\begin{tabular}{|c|c|c|c|c|c|}
\hline \multirow[t]{2}{*}{ Model } & \multicolumn{2}{|c|}{$\begin{array}{c}\text { Unstandardized } \\
\text { Coefficients }\end{array}$} & $\begin{array}{l}\text { Stand } \\
\text { ardize }\end{array}$ & $\mathrm{t}$ & Sig. \\
\hline & B & Std. Error & Beta & & \\
\hline $\begin{aligned} & \text { (Cons } \\
1 & \text { tant })\end{aligned}$ & 7,120 & 3,948 & & 1,803 &, 040 \\
\hline $\mathrm{X}$ & ,791 & ,097 & ,808 & 8,127 &, 000 \\
\hline
\end{tabular}
didapatkan hasil sebagai berikut:

Hasil uji linier sederhana

Coefficients $^{\mathrm{a}}$

Berdasarkan tabel di atas diketahui bahwa nilai koefisien dari persamaan regresi dari output didapatkan model persamaan regresi:

$$
Y=7,120+0,791 X
$$

Dimana :

Y : Disiplin Karyawan

a : konstanta

b : koefisien Regresi

$\mathrm{X} \quad$ : Kompensasi

Hasil persamaan regresi, nilai konstanta sebesar 7,120 artinya apabila terdapat kompensasi $(\mathrm{X}=0)$ maka koefisien regresi disiplin karyawan sebesar 7,120. Koefisien regresi variable Kompensasi (X) sebesar 0,791 artinya kompensasi mangalami kenaikan 1\% maka disiplin karyawan (Y) akan mengalami peningkatan sebesar 0,791 .

\section{Koefisien Determinasi}

Untuk mengetahui besarnya pengaruh variabel independen (Kompensasi) terhadap variabel dependen (Disiplin Karyawan), dihitung dengan uji koefisien determinasi. Besarnya persentase variabel independen

\begin{tabular}{|c|c|c|c|c|}
\hline \multicolumn{5}{|c|}{ Model Summary } \\
\hline Model & $\mathrm{R}$ & $\begin{array}{c}\mathrm{R} \\
\text { Square }\end{array}$ & $\begin{array}{c}\text { Adjuste } \\
\text { d R } \\
\text { Square }\end{array}$ & $\begin{array}{l}\text { Std. Error of } \\
\text { the Estimate }\end{array}$ \\
\hline 1 &, $808^{\mathrm{a}}$ & ,654 & ,644 & 5,17788 \\
\hline
\end{tabular}
dapat menjelaskan variabel dependen dapat diketahui dari besarnya nilai koefisien $\mathrm{R}$ Square. Hasil koefisien determinasi yang sudah disesuaikan dapat dilihat pada :

Hasil Uji Koefisien Determinasi

Dari tampilan output SPSS model summary, besarnya R Square adalah 0,654, artinya bahwa sumbangan pengaruh variabel 
independen (Kompensasi) terhadap variabel dependen (Disiplin Karyawan) adalah sebesar $65,4 \%$, sedangkan sisanya sebesar 34,6\% dipengaruhi oleh variabel lain yang tidak dimasukkan dalam model regresi ini.

\section{Uji Hipotesis}

\section{Uji Parsial}

Penetapan Hipotesis (H0) dan Hipotesis Alternativ (Ha) dibantu dengan SPSS 20, dengan Uji statistik t untuk menguji pengaruh variabel independen terhadap variabel dependen. Untuk mengetahui ada tidaknya pengaruh variabel independen terhadap variabel dependen dapat dilihat pada tabel, jika nilai propabillity $\mathrm{t}<0,05$ maka Ha diterima, sedangkan jika nilai probability $\mathrm{t}>$ 0,05 maka Ha ditolak.

\section{Hasil Uji Statistik t}

\begin{tabular}{|c|c|c|c|c|c|}
\hline \multicolumn{6}{|c|}{ Coefficients $^{\mathrm{a}}$} \\
\hline Model & \multicolumn{2}{|c|}{$\begin{array}{l}\text { Unstandardized } \\
\text { Coefficients }\end{array}$} & $\begin{array}{l}\text { Stand } \\
\text { ardize }\end{array}$ & \multirow[t]{2}{*}{$\mathrm{t}$} & \multirow[t]{2}{*}{ Sig. } \\
\hline & B & $\begin{array}{l}\text { Std. } \\
\text { Error }\end{array}$ & Beta & & \\
\hline $\begin{array}{l}\text { (Cons } \\
\tan t)\end{array}$ & 7,120 & 3,948 & & 1,803 & $\begin{array}{r}, 04 \\
0\end{array}$ \\
\hline$X$ & ,791 & ,097 & ,808 & 8,127 & 0 \\
\hline
\end{tabular}

Dari tabel diatas dapat diketahui tingkat signifikasi variabel independen. Dari variabel independen yang dimasukan dalam model regresi menghasilkan nilai yang signifikan $p_{\text {value }}<0,05$. Maka untuk penetapan taraf signifikan adalah:

$$
\begin{aligned}
\mathbf{d f} & =\mathbf{n}-\mathbf{k}-\mathbf{1} \\
\mathbf{d f} & =\mathbf{3 7} \mathbf{- 2} \\
& =35
\end{aligned}
$$

\section{Dimana :}

df : Degree of freedom

n : Jumlah Sampel

k : Jumlah Variabel X

$\mathrm{t}$ tabel $=1,690($ lihat di tabel $\mathrm{t})$

Maka diperoleh 8,127 > 1,690. Dengan demikian berarti bahwa Kompensasi berpengaruh secara positif terhadap disiplin Karyawan. Dengan demikian pula diperoleh nilai signifikan sebesar $0,000<0,05$ yang berarti terdapat pengaruh yang signifikan. Maka dapat disimpulkan $\mathrm{HO}$ ditolak dan $\mathrm{Ha}$ diterima.

Pengaruh Kompensasi terhadap Disiplin Karyawan

Adapun hasil yang diperoleh dari pengolahan data dengan SPSS versi 20 for windows adalah sebagai berikut:

1. Analisis Regresi Sederhana

Adapun persamaan regresi berdasarkan hasil perhitungan SPSS di atas sebagai berikut:

$$
\begin{gathered}
\mathrm{Y}=\mathbf{a}+\mathbf{b X} \\
\mathrm{Y}=\mathbf{7 , 1 2 0}+\mathbf{0 , 7 9 1 X}
\end{gathered}
$$

Dimana :

Y : Disiplin Karyawan

a : konstanta

b : : koefisien Regresi

X : Kompensasi 
dari perhitungan menunjukan bahwa koefisien regresi variable kompensasi terhadap disiplin karyawan adalah sebesar 0,791 . Angka ini bernilai positif, artinya kedua variabel tersebut memiliki hubungan yang searah. Ini menunjukan bahwa disiplin karyawan PT. Putera Papan Hutama dipengaruhi oleh kompensasi. Semakin baik kompensasi yang diberikan perusahaan, maka disiplin karyawan akan semakin meningkat.

a. Koefisien Determinasi

Adapun hasil perhitungan nilai Koefisien Determinasi adalah sebesar 65,4\%. Hal ini menunjukan bahwa pengaruh antara kompensasi terhadap disiplin Karyawan adalah sebesar $65,4 \%$, sedangkan sisanya sebesar 34,6 \% dipengaruhi oleh variabel lain yang tidak dimasukkan dalam model regresi ini.

\section{b. Pengujian Hipotesis}

Berdasarkan hasil uji statistik $t$ pada tabel 4.41 menunjukan $t_{\text {hitung }}$ untuk Kompensasi sebesar 8,127. Besarnya $t_{\text {tabel }}$ pada $\alpha=0,05$ adalah sebesar 1,690 . Besarnya $t_{\text {hitung }}$ untuk Kompensasi sebesar 8,127 > dari tabel dengan angka signifikansi $0,000<0,05$. Dengan demikian dapat disimpulkan bahwa secara parsial kompensasi berpengaruh positif dan signifikan terhadap Disiplin Karyawan.

\section{SIMPULAN}

Berdasarkan hasil penelitian, terdapat pengaruh yang signifikan antara kompensasi terhadap disiplin karyawan di PT. Putera Papan Hutama sebagai mana ditunjukan oleh hasil koefisien determinasi besarnnya $\mathrm{R}$ square adalah 0,654, artinya bahwa sumbangan pengaruh variabel independen (Kompensasi) terhadap variabel dependen (Disiplin Karyawan) adalah sebesar $65,4 \%$, sedangkan sisanya sebesar 34,6 \% dipengaruhi oleh variabel lain yang tidak dimasukkan dalam penelitian ini. Misalnya gaya kepemimpinan, dan motivasi.

\section{DAFTAR PUSTAKA}

Anwar Prabu Mangkunegara (2013), Manajemen Sumber Daya Manusia, penerbit PT. REMAJA KARYAROSADA Bandung

Didit Darmawan (2013), Prinsip-prinsip Perilaku Organisasi penerbit pena Semesta (PT. Jepe Press Media Utama) Surabaya

Faustino Cardoso gomes(2003), Manajemen Sumber Daya Manusia Penerbit Andi Yogyakarta

Irham Fahmi (2012), Manajemen Teori, Kasus, dan Solusi, penerbit ALFABETA Bandung

Malayu, S.P. Hasibuan (2012), Manajemen Sumber Daya Manusia penerbit Bumi Aksara Jakarta

Marwansyah (2014), Manajemen Sumber Daya manusia, penerbit AFABETA Bandung

Mulyadi (2015), Manajemen Sumber Daya Manusia, penerbit IN MEDIA Jakarta 
Sugiyono (2015), Metode Penelitian Reserch and Development penerbit ALFABETA Bandung

Sukmadi (2012), Dasar-Dasar Manajemen penerbit HUMANIORA Bandung

Suparno Eko Widodo (2014), Manajemen Sumber Daya Manusia, penerbit pustaka pelajar Yogyakarta 